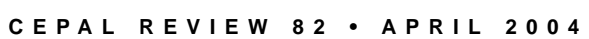

\title{
Regional integration and
} macroeconomic coordination in Latin America

\author{
Hubert Escaith
}

$\mathrm{T}$

he contagion aspects of the financial and exchange-rate crises in recent years demonstrate the need to extend the domain of macroeconomic policy from the national dimension to the regional one. This paper presents the main concepts and challenges behind macroeconomic policy cooperation in Latin America and the Caribbean and evaluates them from a game-theory perspective. Under certain conditions related to the debate on optimal currency areas, entering into a cooperative dynamic will be beneficial for all participants. Moreover, it is shown that because the welfare gains from regional cooperation are endogenous, cooperation will eventually become stable, even in the presence of a Prisoner's Dilemma. Albeit promising at the subregional level, however, the initial conditions observed in Latin America are still far from the conditions of self-sustained dynamics. At the initial stage of coordination, cooperation is unstable, and a formal institutional setting is needed to start and coordinate the cooperative

Hubert Escaith

Director, Statistics and

Economic Projections

Division, ECLAC

- hescaith@eclac.cl process. In addition, more traditional policies of trade integration should be pursued. 
I

\section{Introduction}

The early 1990s opened a new era for the analysis of economic interactions among the Latin American and Caribbean countries. Shocks were transmitted by two channels: real and financial. Intra-regional trade recuperated strongly thanks to the wave of trade liberalization and the resumption of economic growth after the "lost decade" that marked the 1980s. The first years of the 1990s also coincided with the large scale introduction of new financial instruments that allowed operators to trade riskier papers, opening the door to an active market of financial titles issued by the so-called "emerging economies". As a result of this innovation, the settlement of the old debt problem through the Brady agreement, and an increasing flow of foreign direct investment, the net transfer of resources to the region became once again positive, and growth resumed.

But the resumption of growth was accompanied by higher volatility, due to the nature of the new international financial market, where contagion and herding have become a prominent reality. As a result, shocks initiating in one country will have direct impacts upon trade and other real variables, financial spreads and exchange rates in its neighbouring geographical area, as well as upon the international business climate, if the troubled country is large enough (e.g., Argentina, Brazil or Mexico). This common destiny, in spite of differences in policies or fundamentals from one country to another, is a clear symptom of the emergence of a subregional dimension as a result of trade integration and financial globalization (Studart, 2002)

\footnotetext{
$\square$ This paper is based on a number of separate contributions made to a research agenda on regional integration, exchange rate regimes and macroeconomic coordination, implemented in the framework of the ECLAC/European Commission Macroeconomic Dialogue Network (REDIMA). The arguments presented here benefited greatly from the discussions, comments and suggestions of Christian Ghymers, Igor Paunovic and Rogerio Studart, as well as the network participants. Needless to say, I alone am responsible for any remaining errors and analytical gaps.
}

Because of this common component, national macroeconomic stability (including its real aspects) should now be treated as a regional public good. The existence of such externalities calls for more coordination of national economic policies in the region. Despite these interdependencies, and notwithstanding major initiatives to promote macroeconomic coordination in several subregions of Latin America and the Caribbean, cooperation does not always emerge naturally, even though it would be optimal for it to do so. Reflecting on this situation, Escaith, Ghymers and Studart (2002) state that "it is striking that there is no systematic, operational regional or subregional scheme to deal with these regional or subregional spillovers... Indeed, economic policies are still totally uncoordinated and all the decisions continue to be taken in close-knit national circles without considering any spillovers at all. The clearest symptom of this is the choice of exchange-rate regimes based on strictly national considerations."

In other words, and considering the macro-economic coordination problem from a game-theory perspective, it is obvious that the dominant "non-coordinated" strategies adopted by the countries of Latin America and the Caribbean do not coincide with the social optimum that could be achieved by incorporating regional cooperation. Ghymers (2001) considers that most institutional failures from a regional coordination perspective can be analyzed from the Prisoner's Dilemma perspective.

Starting from this premise, the present essay shows that, by incorporating recent conceptual advances in the theory of currency unions, macroeconomic coordination within regional integration schemes provides a feasible and robust solution to the Prisoner's Dilemma. The criteria for the existence of a solution are then compared with the statistical regularities observed in the region. Finally, section IV describes the institutional settings that would make possible such coordination, and section $\mathrm{V}$ synthesizes the main findings. 
II

\section{Macroeconomic coordination, the Prisoner's Dilemma, and the problem of inefficient equilibrium}

As described in Ghymers (2001), one of the main obstacles to regional cooperation is the belief that there is a conflict between national interest and regional integration. According to this author, although most governments understand that coordinated policies would, in a perfect world, be the most suitable way of dealing with the issues and challenges presented by globalization, practical criteria lead them to implement non-coordinated policies aimed at optimizing purely national and short-sighted objectives. This situation, where individual rationality impedes coordination, is known as the Prisoner's Dilemma.

\section{Cooperation and the Prisoner's Dilemma}

The so-called Prisoner's Dilemma is an unfortunate social situation where myopic and selfish attitudes dominate, despite the fact that cooperation would be the best policy from a social perspective. In other words, it is a game where each player has an incentive to play in a non-cooperative way, either because playing dirty maximizes one's personal reward if the other party plays fair (i.e., follows a cooperative strategy), or minimizes one's losses if the other party decides to defect from the cooperative agreement and plays dirty himself.

The name comes from a story used by A.W. Tucker. Two suspects are taken into custody, cannot communicate with each other, and have two options: either to confess or not to confess the crime. If both confess, they will receive a jail sentence of five years. If neither confesses, they will probably be convinced of minor offences and receive a one-year sentence each. But if one confesses and the other does not, the suspect who confesses will be set free, while the other will receive a ten-year sentence. In this game, the dominant individual (non-cooperative) strategy is not to trust the other prisoner and confess to avoid the maximum punishment.

Technically, the equilibrium in this game is not a
Pareto optimum: both players would be better off it they opt for not confessing. Table 1 represents symbolically the strategies and outcomes of a $2 \times 2$ ordinal game that leads to a Prisoner's Dilemma. Strategies C are for cooperation, and D for defection. R stands for the reward for mutual cooperation, $\mathrm{T}$ for the temptation to defect from that approach, $\mathrm{P}$ for the punishment in the event of mutual defection, and S for the sucker's payoff to the player who cooperates when the other does not.

TABLE 1

Symbolic representation of a $2 \times 2$ Prisoner's Dilemma game

\begin{tabular}{lcc}
\hline Player A $\backslash \mathrm{B}$ & Cooperate $(\mathrm{C})$ & Defect (D) \\
\hline Cooperate $(\mathrm{C})$ & $(\mathrm{R}, \mathrm{R})$ & $(\mathrm{S}, \mathrm{T})$ \\
\hline Defect $(\mathrm{D})$ & $(\mathrm{T}, \mathrm{S})$ & $(\mathrm{P}, \mathrm{P})$
\end{tabular}

Source: Prepared by the author.

A game is basically defined as a Prisoner's Dilemma when, for both players, $\mathrm{T}>\mathrm{R}>\mathrm{P}>\mathrm{S} .{ }^{1}$ This ranking ensures that each player has a dominant strategy that results in an equilibrium with a Pareto-inferior outcome. In such a situation, players - be they individuals, firms or States - that follow the irrefutable logic of purely rational and selfish strategies may find themselves caught in a sub-optimal situation.

Hence, it is not easy to attain spontaneously a cooperative equilibrium. Unless there is a credible and enforceable commitment on the part of the players, or coordination by an external referee, cooperation will remain elusive, even if the players are allowed to communicate with each other in advance: each player has an incentive to play in a non-cooperative way. When generalized to more than two players, this becomes a version of the so-called "Tragedy of the Commons"

\footnotetext{
1 Another condition, applying to repeated games, is that the players cannot get out of their dilemma by taking turns to randomly exploit each other. This means that $\mathrm{R}>(\mathrm{T}+\mathrm{S}) / 2$ (Axelrod, 1984).
} 
(Hardin, 1968). Decisions that are rational from the point of view of each individual become defective from the collective point of view.

One way out of the dilemma is to consider that the players have the option of building agreements through communication. Clearly, if the parties are able to negotiate a binding agreement, the dilemma disappears. Penalties may be built in to punish uncooperative behaviour, so that for each player $\mathrm{R}>\mathrm{T}>\mathrm{P}>\mathrm{S}$. Obviously, in the case of sovereign countries, which are the actors to be considered in the macroeconomic coordination game, international agreements-cumpenalties (such as the Maastricht Treaty in Europe) are not always legally enforceable, and could be subject to abrogation or renegotiation if one party considers that its "higher" State interests are at stake.

Thus, communication by itself does not solve the dilemma in this context, and the problem of governments is how to make credible commitments. This typical macro-policy problem could also be studied from the game-theory point of view. Indeed, it is still possible to reach a cooperative outcome without a formal binding contract, when games are considered in a dynamic perspective. Time is an important factor is resolving cooperation deficits. The fact that players have to meet again and again pave the way for "nice" strategies to develop, even when players are selfish: cooperation is based upon self-interest, without the aid of central or supra-national authorities. Two key requisites for cooperation to thrive in this context are that the cooperation must be based on reciprocity, and the weight of future outcomes must be important enough to make this reciprocity stable.

Players in real life, be they individuals, firms, or countries, do not play the game just once, but interact over and over again. Thus, each player can develop a reputation and earn credibility ${ }^{2}$ about his behaviour and learn about other players' conduct. The players not only learn about each other's behaviour, but also become capable of rewarding cooperative forms of conduct (strategy C) or punishing uncooperative ones (D).

This strategy is called the Tit-for-Tat strategy: player A starts out cooperating, and continues to do so as long as the other player B cooperates. If B does not

\footnotetext{
2 The concepts of reputation and credibility in game theory are very complex and require assumptions about the degree of rationality of players, asymmetric information, the different characters of the players, and many other ingredients. Since our purpose is only to present basic concepts of game theory, we have tried to make all this as simple as possible.
}

cooperate and plays the D strategy, there is still time to counter attack with one's own D strategy, and avoid the disastrous CD or DC outcomes. This Tit-for-Tat strategy is the best alternative when games are infinitely repeated or at least repeated with a sufficient number of iterations. When games are finite, however, there is a high probability that the other (perfectly rational) player will use the selfish and uncooperative strategy in the last occurrence of the game, since the other player does not have the possibility to retaliate. Because of the same reasoning, there will be no cooperation at the next-to-last occurrence, and so on.

However, cooperation may prevail, because in real life the hypothesis of pure rationality and pure selfishness is not always representative of the actual behaviour of players. As demonstrated by Axelrod (1984), cooperation can emerge even in a world of unconditional defection, if at least some of the players are willing to initiate the game using a cooperative ("nice") strategy. Cooperation can evolve from small clusters of individuals who base their cooperation on reciprocity and have even a small proportion of their interaction with each other. In the author's words "The most promising finding is that, if the facts of Cooperation Theory are known by the participants with foresight, the evolution of cooperation can be speeded-up." (Axelrod, 1984, p.24).

\section{Costs and benefits of coordination}

The technical part of the discussion about the benefits and costs associated with macroeconomic coordination is usually analysed from the standpoint of the Optimal Currency Areas criteria (OCA). ${ }^{3}$ Countries considering whether to adopt the currency of a third country (e.g., dollarization) or to join a currency union (e.g., the European Economic and Monetary Union) weigh the potential benefits against the expected costs. Since Mundell (1961) developed the concept of OCA, the criteria are defined in terms of trade relationship and symmetry or asymmetry of external shocks. The greater the linkage, the more desirable a union; to compensate for imperfections in the first two criteria, two additional ones are considered: degree of labour mobility and/or system of fiscal transfers.

In the Mundell-Fleming model, then, the nature

\footnotetext{
3 See Escaith and Paunovic (2003) for examples of fiscal cooperation.
} 
of the exchange rate regime determines the degree of freedom for using monetary policy as a response to external (real) shocks. In a pegged regime, a shock would be transmitted directly to the economy through the reduction/increase in international reserves and the resulting reduction/increase in the money supply and hence, given nominal rigidities, in aggregate demand. A flexible exchange rate would permit more flexible use of monetary policy to counteract the external shock and adjust relative prices, at the expense of higher inflation levels.

According to Mundell (1961), ${ }^{4}$ currency area optimality occurs when the benefits of relinquishing the exchange rate as an internal adjustment instrument outweigh the costs of adopting a single currency in a fixed exchange regime. These criteria indicate the specific conditions under which it is advantageous for a group of economies to adopt a single currency, based on an analysis of the (microeconomic) gains of efficiency and the (macroeconomic) costs of the loss of flexibility.

The usefulness/sustainability of an OCA is often determined as a function of labour mobility, economic size and openness, similarity of production structure and the symmetry (or asymmetry) of economic shocks. Deep trade interrelationships, symmetrical exposure to external shocks and synchronization of business cycles increase the expected net benefits of adopting a common currency and a common monetary policy. Indeed, shocks affecting all the countries in a similar fashion, at the same point in their business cycle, do not call for a change in exchange rates. Labour market flexibility and mobility reduce the real adjustment costs when shocks and cycles are not perfectly symmetrical, while the existence of fiscal compensation schemes opens up the possibility of transfers between losers and winners.

Despite their theoretical interest and the qualitative guidance they provide, the practical usefulness of OCA criteria is limited. In particular, they are not fully operational for decision-making purposes, as in practice they cannot be used to quantify a balance of costs and benefits (McCallum, 1999). Moreover, a more recent trend in the literature centres on two empirical questions that reassess the relevance of the abovementioned OCA criteria.

The first of these questions examines the problem of the balance between costs and benefits by revising

\footnotetext{
4 McKinnon (1963) and Kenen (1969) are also important contributors to the standard literature on OCAs.
}

the actual cost for a country of losing the ability to use the exchange rate as a policy instrument and looks at the effectiveness of nominal adjustments of the exchange rate. When an economy suffers a nominal shock, adjusting parities is not an adequate instrument, and a regime with a fixed exchange rate will do better in terms of welfare. ${ }^{5}$ Indeed, the exchange rate is potentially useful as an instrument in situations when shocks are simultaneously country-specific, real and temporary. According to this literature, the probability of such situations is becoming smaller as trade integration reduces the significance of national borders and as stability-oriented policies curtail policyinduced shocks. Furthermore, contemporary advocates of monetary unions think that the pure and perfect exchange-rate flexibility option is not the correct alternative when discussing costs and benefits of OCAs, because modern-day trade and financial interrelationships make pure flexibility a nonviable option (Buti and Sapir, 1998).

The second "revisionist" trend in the OCA literature is of special interest from the point of view of the present essay. Regional trade integration increases business-cycle correlation and promotes new institutional initiatives that will set up a positive feedback loop for intraregional trade itself. Thus, cooperation creates its own conditions of sustainability. In the following section, we will discuss these aspects in greater detail and show how they apply to the Prisoner's Dilemma issue.

\section{Dynamic gains from regional coordination of macroeconomic policies}

As already noted, recent developments in the positive theory of OCA and the European Monetary Union (EMU) experience show that the optimality criteria are in fact endogenous. As stated by Frankel and Rose (1996), and as illustrated by the case of the European Union, the suitability of OCA criteria cannot be judged on the basis of historical data, since the structure of the national economies - especially their trade structure will be affected by the creation of a currency area and is likely to change. In those authors' words, the OCA criteria are jointly endogenous:

"Countries are likely deliberately to link their currencies to those of some of their most important

\footnotetext{
5 See Parrado and Velasco (2002).
} 
trading partners, in order to capture gains associated with greater exchange rate stability. In doing so, they lose the ability to set monetary policy independently of those neighbors. The fact that their monetary policy will be closely tied to that of their neighbors could result in an observed positive association between trade link and income links. In other words, the association could be the result of countries' application of the OCA criterion, rather than an aspect of economic structure that is invariant to the exchange rate regimes." (p. 15).

As a consequence, the authors state in their conclusion (p. 22) that "some countries may appear, on the basis of historical data, to be poor candidates for EMU entry. But EMU entry per se, for whatever reason, may provide a substantial impetus for trade expansion; this in turn may result in more highly correlated business cycles. That is, a country is more likely to satisfy the criteria for entry into a currency union ex post than ex ante."

In this endogenous framework, regional monetary and exchange rate coordination can be represented by a new kind of a non-zero sum game, where the positive outcome increases when the game is repeated: the more you play, the more you gain. Because of objective reasons, linked to the OCA criteria (weaknesses of trade and financial integration, asymmetry of business cycles), and subjective factors (reduced credibility of regional commitments and weak institutional enforcement procedures), initial gains from consensuating regional policy response to external shocks may be low compared with the outcome of non-cooperative strategies. We recognize here the typical Prisoner's Dilemma problem, where the structure of incentives is perverse. But because of the endogenous nature of the OCA criteria, as time goes by and the more countries interact, the higher is the welfare gain obtained from coordination and the lower the temptation to defect.

If we go back to the formal representation of the
Prisoner's Dilemma (table 1), the gain from cooperation $R(t)$ depends positively on the number of times the game is repeated $(t)$.

\section{$d R / d t>0$}

Figure 1 gives a tree representation of this game. The first letter in parentheses denotes the strategy of A, while the second is the strategy of B. For simplicity, let us assume that B applies a tit-for-tat strategy. Both countries cooperate in the initial round and gain $R_{0}$.

- If A defects in the first iteration, he gains $\mathrm{T}$ and $\mathrm{B}$ suffers the $\mathrm{S}$ outcome, but both gain only $\mathrm{P}$ in the second round, once B applies the tit-for-tat countermove.

- If A cooperates, both countries gain $R_{l}$, with $R_{1}>R_{0}$.

The same reasoning applies to subsequent moves, with $R_{t}>R_{(t-l)}$.

Thanks to the endogenous and incremental nature of $R_{t}$ in this class of games, the gains from cooperation should increase with time such as to reach the situation when $R\left(t^{*}\right)>T$. Remember that a Prisoner's Dilemma exists only when, for both players, $T>R>P>S$ and the dominant strategy dictates that each player should defect and follow a non-cooperative strategy. After repeating the game up to time $t^{*}$, welfare gains from cooperation increase to a point where defecting is no longer the dominant strategy (see figure 2 for a graphic representation of the outcome of the cooperative game).

Obviously, the initial stages of the cooperative game are critical for its success, when $R t$ is lower than $T$ or too close to it, thus making the net gain from cooperation too uncertain. This caveat is particularly important when referring to the Latin American situation, where the initial degree of trade and financial integration is weaker than in the European case.

FIGURE 1

Game tree representation

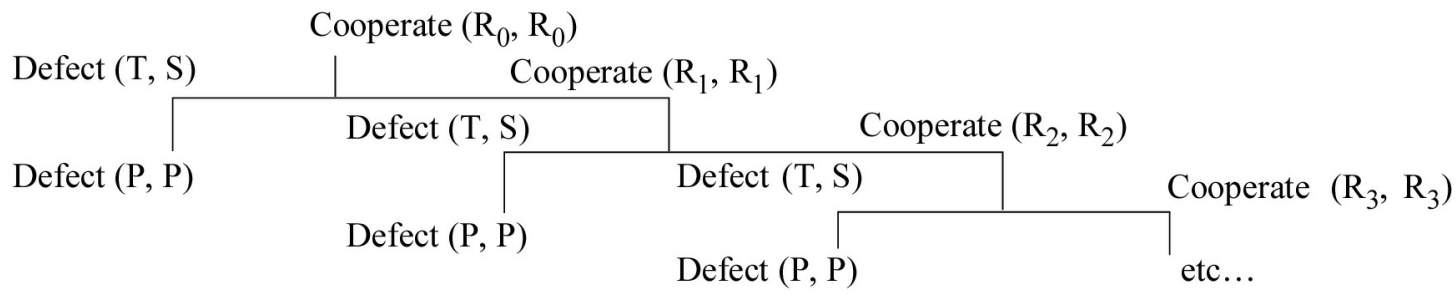




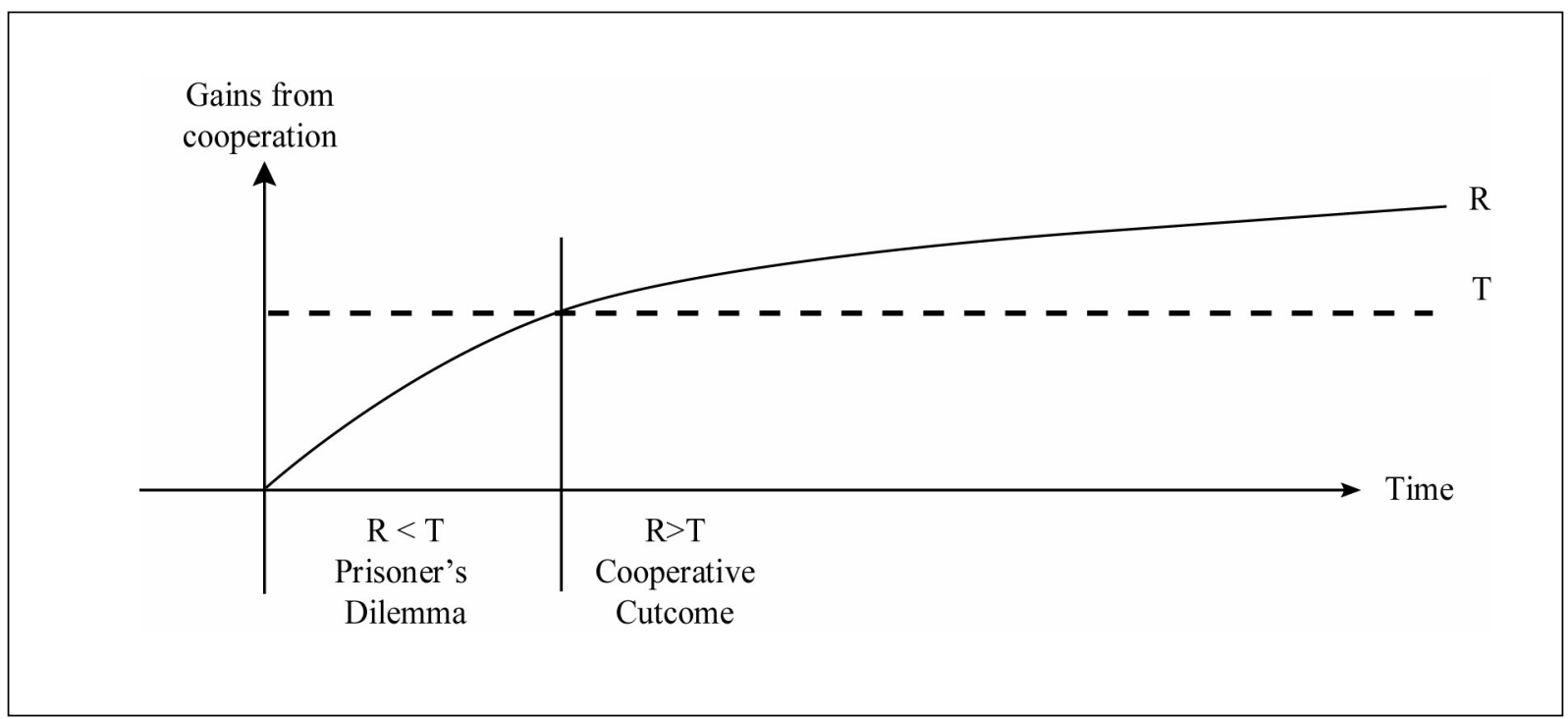

Source: Escaith and Paunovic (2003).

\section{III}

\section{Economic convergence, integration and policy coordination in Latin America}

As already noted, despite their limitations OCA criteria are a good starting point to look at the feasibility of initiating a dynamic process of policy coordination in a regional framework. The issue depends not only on national considerations, but also on externalities linked to the regional dimension of the transmission of shocks.

The evolution of the Latin American and Caribbean economies since the mid-1980s shows a convergence in terms of macroeconomic policies and achievements. Confronted with the negative shock of the debt crisis of 1982, the necessary adjustment following the reversal of net financial resource transfers from the rest of the world and episodes of high to hyperinflation, most countries embarked upon stabilization programmes. These programmes shared a nuclear set of common objectives, strategies and instruments. The increased dependence on external finance during the 1990s also led to a reduction in the freedom of domestic policy makers to diverge from orthodox policies.

The trend not only affected macroeconomic policies stricto sensu, but also brought a deeper transformation of the institutional framework via structural reforms. The evolution of reform indexes (ECLAC, 2001) shows that by the end of the 1990s most Latin American and Caribbean countries had achieved convergence in terms of trade, financial and capital liberalization reforms.

As a result of these trends, most of the countries of the region entered the 2000s with many shared characteristics, not only in their way of thinking about making economic policies, but also in the results -both positive and negative- of those policies. Sharing common objectives, institutional frameworks and instruments provides quite fertile ground for macroeconomic policy coordination. Whether it is optimal to integrate this dimension into the national strategies 
depends in part on the comparative review of their exposure to external shocks. The first aspect to be analyzed is trade integration.

\section{Trade integration}

One of the central factors in macroeconomic policy coordination and OCA is the degree of trade interrelationship between potential partner countries throughout the trade sector. This is traditionally analyzed in terms of trade flows and symmetry of external shocks.

\section{a) Intraregional trade}

Since 1991, with the recovery from the 1982 debt crisis, trade with other Latin American and Caribbean countries, especially within integration subregions (Andean Community, CARICOM, Central American Common Market, Mercosur), has increased much faster than trade with other countries, at least up to 1998. Thus, intraregional trade, which represented $13 \%$ of total exports in 1991, rose to $20 \%$ in 1998: an implicit growth rate of almost $15 \%$ annually in real terms. Due to the crisis in Mercosur and a decline in the Andean group, this share went down to $16 \%$ in 2002, reducing the annual growth rate over the 1991-
2002 period to $9 \%$ (table 2). This growth is particularly significant from our perspective, because trade has grown much more rapidly than the domestic product, increasing its contribution to the level of economic activity.

TABLE 2

Latin America and the Caribbean: Trends in trade and domestic product, 1991-2002

\begin{tabular}{lcc}
\hline \multirow{2}{*}{$\begin{array}{l}\text { Latin America } \\
\text { and the Caribbean (LAC) }\end{array}$} & \multicolumn{2}{c}{ Average annual growth rate } \\
\cline { 2 - 3 } & $1991-1998$ & $1991-2002$ \\
\hline Total supply & 4.5 & 3.3 \\
GDP & 3.3 & 2.5 \\
Imports of goods and services & 12.0 & 8.0 \\
Exports of goods and services & 8.5 & 7.3 \\
\hline
\end{tabular}

Exports to other

$\begin{array}{lll}\text { Latin American countries } & \text { b } & 14.8\end{array}$

Source: Prepared by the author on the basis of ECLAC data.

a Percent, from data at constant 1995 prices

b Estimated from data at current prices.

Economic transactions within each subregional integration scheme have been taking on an increasingly important role (figure 3), not only in quantitative but also, and especially, in qualitative terms: while trade with countries outside the region is composed of

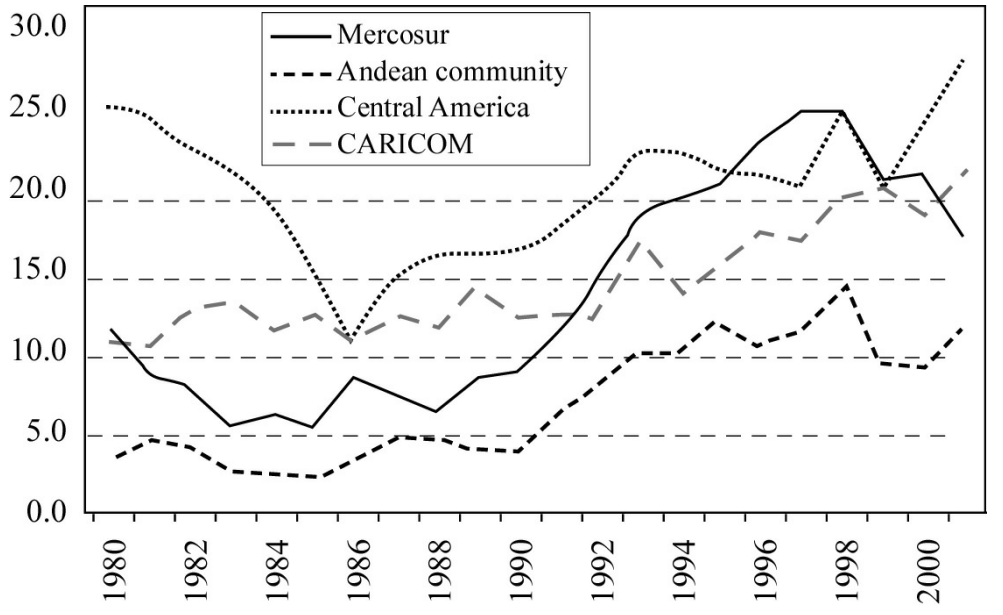

Source: ECLAC (2002a). 
traditional products (commodities or processed primary products), in South America intraregional trade is based on manufactured products, allowing national economies to diversify their export base (Benavente, 2001). Mexico, Central America and the Caribbean countries, on the other hand, have diversified their exports thanks to their privileged access to the United States market ("maquiladora" industries) or their natural advantages in terms of tourism.

This trend has two important (and potentially conflicting) consequences for the purposes of the present paper. First, it increases the transmission of shocks through trade, in the traditional OCA perspective, and thus is a factor of greater interdependence between countries. Second, it increases the potential for conflict between national exchange rate policies, as these exports consist of consumer and intermediary products that are sensitive to relative prices. Thus, devaluation by one of the regional trading partners could have a strong impact on regional trade flows, triggering regional tensions (as occurred in Mercosur after devaluations in Brazil or Argentina) or competitive devaluations (as in Europe in the late 1970s). Obviously, these cross-effects are directly relevant to both the choice of national exchange rate regime and the potential gains from regional coordination. ${ }^{6}$

\section{b) Terms of trade}

In small open developing economies, terms of trade fluctuations (variations in the prices of a country's exports relative to those of its imports) are a major source of instability. Structural characteristics make export prices very volatile because of the high proportion of commodities and there is little capacity for substituting imports internally (because of their higher technological content), even when their relative prices increase. Non-transitory shifts in relative prices, as exemplified by structural trends in terms of trade is an issue that has been receiving attention for quite a long time. ${ }^{7}$

Short-term fluctuations in relative prices are perhaps more damaging to investment than long-term trends, as volatility increases systemic uncertainty and diminishes the capacity for sound decision-making. These fluctuations are also more relevant when it comes to macroeconomic policy coordination, especially when the explicit objective of that policy is to stabilize nomi-

\footnotetext{
6 See CEI (2003) for a review of the cooperation issues from a Mercosur perspective.

7 See Ocampo and Parra (2003).
}

nal and real variables, i.e., to smooth out high-frequency fluctuations.

As shown in figure 4, the dynamics of terms of trade has been quite different across countries over the past ten years in terms of trends 8 and volatility. As an annual average over the 1991-2002 period, six countries out of nineteen suffered negative shocks and eleven had positive ones. This resulted in a small positive annual average of $0.2 \%$ for the region as a whole $(0.6 \%$ as a simple average of individual countries), the extremes ranging from $-2.4 \%$ (Nicaragua) to $3.7 \%$ (Venezuela).

Volatility is very different from country to country, with standard deviations ranging from as low as 2.6 in Mexico, which has the advantage of a diversified export structure, to as high as 21.6 in Venezuela, a monoexporter of oil. The volatility for consolidated exports is low for the region as a whole (3.4 when all exports are consolidated), but reaches 8.1 if computed as a simple average of the countries.

Looking at the correlation between countries, one notes that most countries in the region share a common positive interdependence, while a small group evidences diverging behaviour. This is best seen from section B of figure 4 , which shows the clustering of the Latin American and Caribbean countries according to a breakdown of the principal components of their terms of trade variations. On the first two axes, which jointly explain $65 \%$ of total variance, one may note a first cluster of countries in the northwest quadrant, composed of Ecuador, Venezuela, Argentina and, to a lesser degree, Colombia and Mexico. These are oil-exporting countries. Panama is isolated because of its specificity as a processing and transit zone.

Except for Bolivia, all the other countries of the region are clustered into a compact group in the western part of the figure. This cluster includes all the countries in the Central American Common Market and almost all the Mercosur countries except Argentina. This means that the countries from these two integration areas share the same (short-term) trends for terms-oftrade variations, which is an important basis for coordinating a regional response to common external shocks. The situation of the Andean countries is more diversified from this point of view, because of their respective specialization in oil exports (Ecuador and Venezuela, but also Colombia) or in other minerals (Bolivia, Peru).

\footnotetext{
8 The term "trends" is used here in the sense of tendency, and does not refer to what statisticians may understand by deterministic trends (e.g., in contrast to random movements).
} 


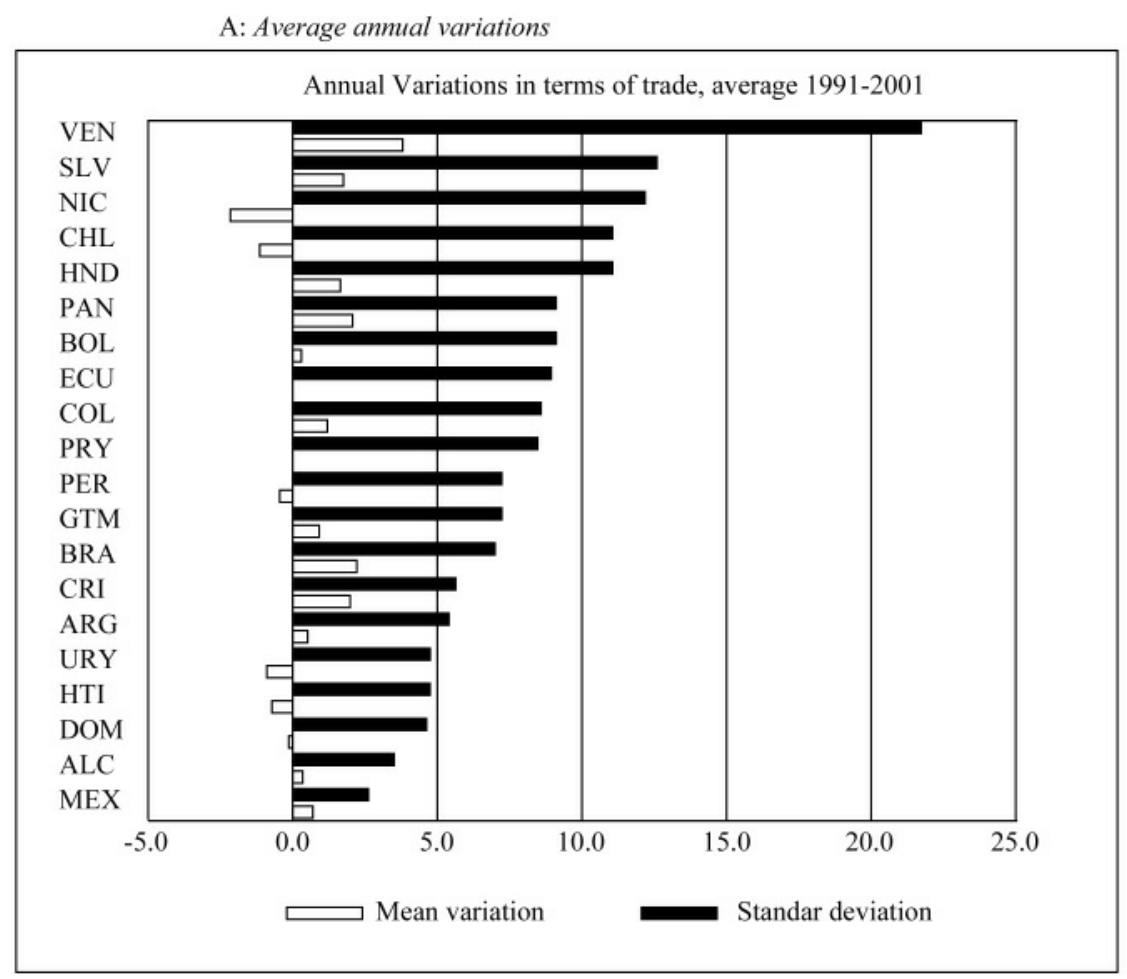

B: Correlations circle on axes 1 and 2 (65\% of total variance)

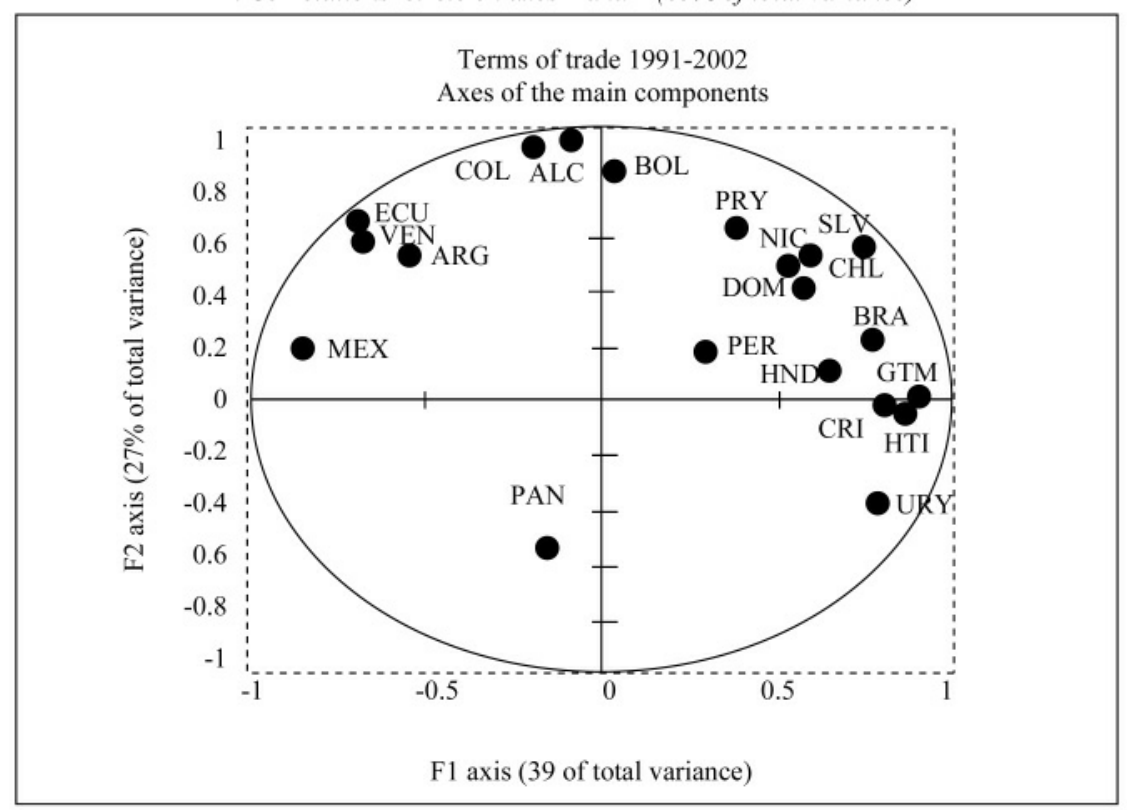

Source: Prepared by the author on the basis of ECLAC data.

REGIONAL INTEGRATION AND MACROECONOMIC COORDINATION IN LATIN AMERICA • HUBERT ESCAITH 


\section{c) Effective exchange rates}

Exposure to common terms-of-trade shocks and stronger intraregional trade should lead to greater covariation of effective real exchange rates (ERERs). The calculation of these rates takes into account the evolution of the country's bilateral exchange rates in relation to each of its trading partners, correcting for differences in the respective domestic rates of inflation and weighting for the relative importance of the trading partner in a country's total trade.

The ERER is a widely accepted measure of shortterm macroeconomic competitiveness. As such, it is an important indicator to monitor in any trade integration scheme: when the ERER rises (or decreases), the country in question gains (or loses) competitiveness with regard to the (weighted) average for its trading partner. Obviously, when regional partners account for a significant share of external trade, variations in neighbouring countries' exchange rates (or internal prices) will greatly affect the overall trade competitiveness of each country.

This merely quantitative and mechanical effect is compounded by the potentially greater price elasticity of intraregional trade. Because intraregional trade in Latin America is more intensive in manufactured goods, demand is potentially more sensitive to changes in relative prices than in the case of the goods exported to the rest of world, which in Latin America (and especially in South America) are mainly primary products, whose prices are set internationally. The firms that participate in intraregional commerce are in general smaller than those trading with the rest of the world and more sensitive to transitory changes in relative prices.

Correlation coefficients between the exchange rates of the Latin American and Caribbean countries were calculated from 1992 up to the first semester of 2003 for the quarterly variations of four categories of real exchange rates: i) the bilateral rate with the United States economy, ii) the effective rate with regional trading partners (a weighted average of the bilateral exchange rate, adjusted by the difference in inflation rates), iii) the effective rate with non-regional trading partners (excluding the United States of America), and iv) the effective exchange rate for all trading partners (regional and non-regional). Contemporary correlation coefficients were calculated, thus capturing only the direct and most observable effects. The trading partners were weighted by their exports to the reporting country.
The correlation coefficients obtained for the ERER with regional partners are the most interesting in the present case, as they reflect the intensity of the shocks passed from one country of the region to the others through the exchange rate, either by trade or by other causes. They are clearly a prime indicator of macroeconomic integration. When there are close trade relationships within a subregional integration scheme, a positive impulse in one country (a gain in exchange rate competitiveness) should result in a negative one in the regional trading partners.

By construction, because of the symmetry of trade relationships, the sum of the correlation coefficients is close to zero when considering all the Latin American and Caribbean countries that enter in the calculation of the regional ERER. The closer the intraregional trade relationship, the higher the positive and negative variations. But part of the interaction analyzed through the behaviour of regional ERERs may be due to a third, external, factor to which all countries in the region react simultaneously (an external shock of large magnitude, such as the Asian and Russian crises of 1997-1998, for example). To filter out this noise, the correlation coefficients obtained for real exchange rates with the US dollar were subtracted from the results obtained with the regional ERER. An index was constructed using the sum of the absolute values of the results obtained for each country, normalized by the total across countries (figure 5).

As expected, the largest countries of the region (Argentina, Brazil and Mexico) are among those showing the greatest interaction with the rest of Latin America and the Caribbean. Great care should be taken not to draw definitive conclusions from this index, however. Despite the filtering process used, the index remains subject to "spurious" correlation effects which affect ${ }^{9}$ the results, Also, the index is better calculated on "normal years", because great asymmetrical shocks affecting a smaller economy may create noise in the indexing procedure. For example, Uruguay has been closely integrated into the Mercosur economy and ranked high in the index calculated from 1992 up to 2001 (6.6). The large devaluation of 2002 had no significant impact on the effective exchange rate of Uruguay's trade partners, due to the small size of its economy, and the resulting effect was a drop of

\footnotetext{
9 For example, higher international oil prices can affect the nominal exchange rate of oil exporting countries, such as Venezuela, and the internal rate of inflation of importers, thus affecting simultaneously the ERER of both exporters and importers, even if they do not have close economic relations.
} 


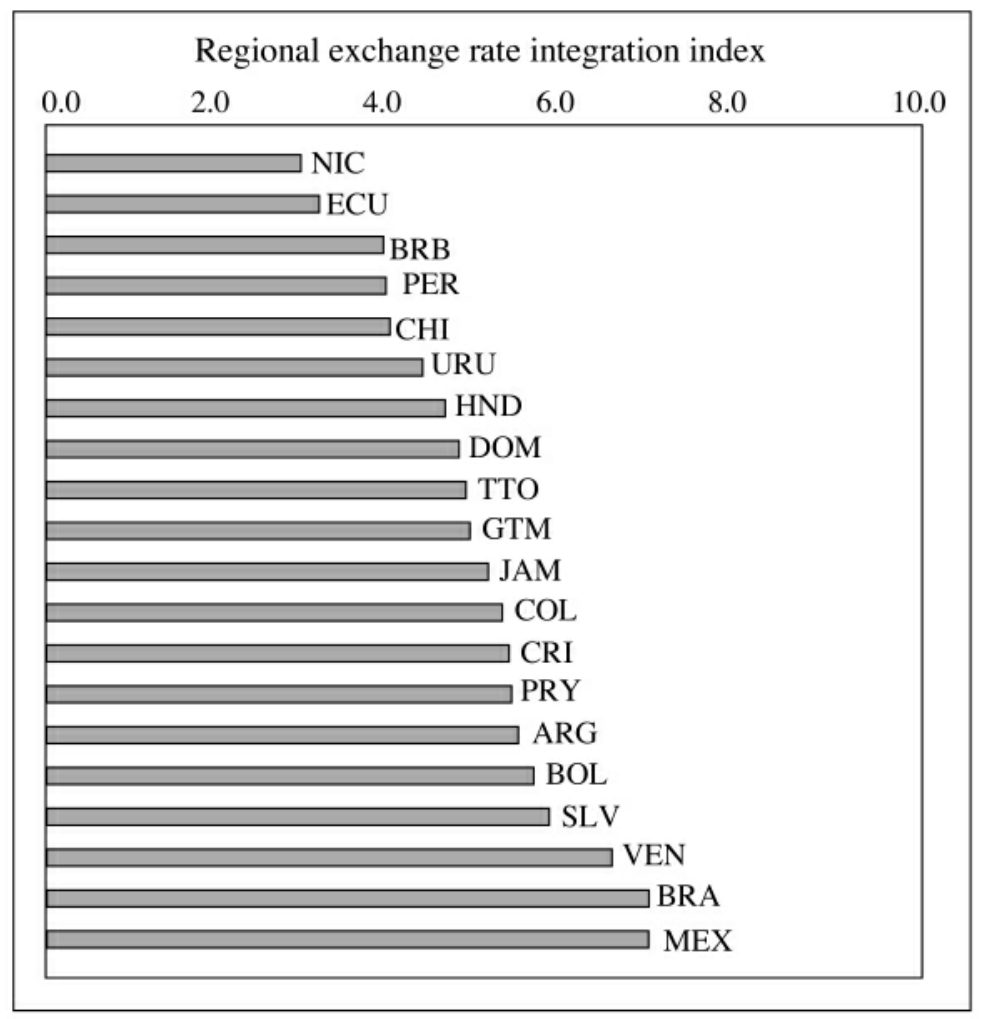

Source: Prepared by the author.

more than two points in its integration index (to 4.4) when the 2002 and 2003 periods are incorporated.

Another conclusion may be drawn when looking at the ERER with non-regional trading partners (excluding the USA). It is striking that i) most elements of the correlation matrix are positive and ii) many have a high value compared with the regional ERER and the bilateral US dollar tables. This intuition is confirmed when principal component analysis is applied to the real exchange rate variations. In this case, the higher the co-movement among the original series, the fewer the common factors needed to "explain" the total variance of the sample. It is clear from table 3 than co-movements are higher when exchange rate variations are considered in relation with "other" trade partners rather than with the USA or regional partners. In the first case, the first factor explains $40 \%$ of the variance: i.e., approximately double the value encountered in the two other cases. The same difference persists when considering second and (albeit less so) third) factors.
TABLE 3

Latin America and the Caribbean: Quarterly real exchange rate variations, 1992-2003: principal component analysis (Results obtained for the first four components)

\begin{tabular}{lrrrr}
\hline & Factor 1 & Factor 2 & Factor 3 & Factor 4 \\
\hline LAC Partners & & & & \\
$\begin{array}{l}\text { Eigenvalue } \\
\text { \% variance }\end{array}$ & 4.4 & 3.5 & 2.7 & 2.3 \\
\% cumulative & 22.2 & 17.5 & 13.4 & 11.5 \\
$\begin{array}{l}\text { Bilateral with USA } \\
\text { Eigenvalue }\end{array}$ & 22.2 & 39.8 & 53.2 & 64.7 \\
\% variance & 3.9 & 2.1 & 2.0 & 1.8 \\
\% cumulative & 19.3 & 10.5 & 10.1 & 8.8 \\
$\begin{array}{l}\text { Other trading partners } \\
\text { Eigenvalue }\end{array}$ & 19.3 & 29.8 & 40.0 & 48.7 \\
\% variance & & & & \\
\% cumulative & 8.0 & 2.6 & 1.6 & 1.3 \\
\hline & 40.0 & 12.9 & 8.0 & 6.3 \\
& 40.0 & 52.9 & 60.9 & 67.2 \\
\hline
\end{tabular}

Source: Prepared by the author. 
It appears that most of the Latin American and Caribbean countries share a common trend with respect to non-US dollar currencies (basically European and Asian currencies in our sample). This is easily explained considering that de facto or de jure these economies belong to the dollar area, and thus tend to share the same exchange rate fluctuations with other international currencies.

\section{Internal economic cycles}

In the previous sections, we looked at the transmission of shocks via terms-of-trade or exchange-rate channels. In view of the high external vulnerability of the region, these shocks would be expected to have an impact on short-term growth dynamics. In the present section, we will look into the coincidence of the "real cycles" within the region. ${ }^{10}$
Two set of indicators are used for this purpose, one being the quarter-to-quarter seasonally adjusted GDP growth rate, and the other the size of the output gap. These were calculated by reference to a medium-term tendency obtained by smoothing real GDP time series, applying the widely used Hodrick-Prescott (HP) filter to the data. A standard value of 1600 was utilized to parameterize the filter, and the quarterly series were extrapolated at both ends of the sample, to reduce the wellknown end-point sensibility of the HP filter.

Tendencies for GDP growth using the filtered series capture the medium-term trends observed during the 1990s up to 2002. Figure 6 shows two different dynamics at the beginning of the present decade. The low-growth subset was composed of South American countries severely hit by the 1997-1999 crisis that affected many emerging economies. This crisis affected in particular the Southern Cone economies, especially in the context of the Argentine turmoil in 2001-2002. Mexico and the Caribbean and Central American coun-

FIGURE 6

Latin America: Evolution of potential GDP, 1993-2002

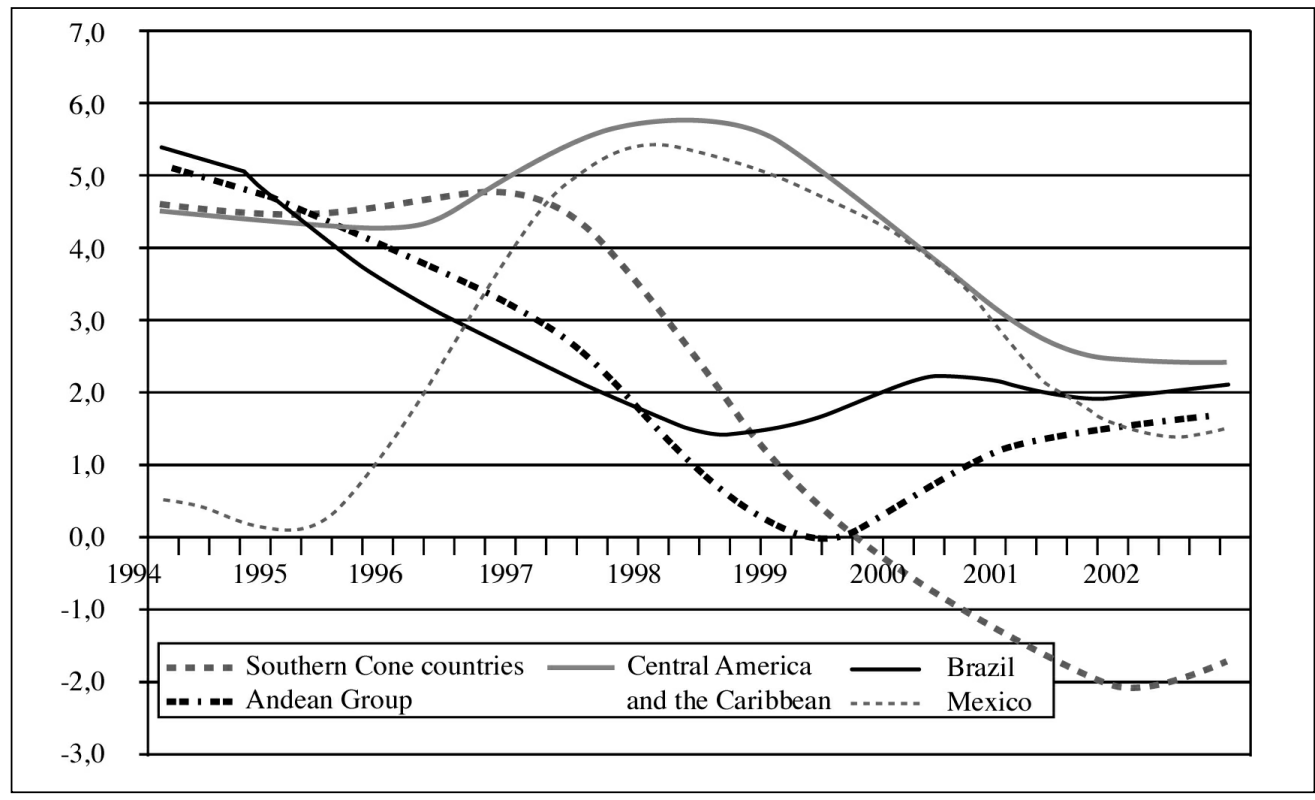

Source: Prepared by the author on the basis of data provided by the ECLAC Economic Projections Centre.

\footnotetext{
${ }^{10}$ In this purely descriptive context, "real cycles" should be understood as GDP fluctuations around an observed trend, and do not refer to the source (monetary or real) of the observed fluctuation.
}

For a more in-depth study on cycle co-movements in Latin America, see Cerro and Pineda (2002). 
tries were able to escape the 1997-1999 turbulence thanks to their closer links to the booming United States economy and lesser dependence on exports based on primary products. When the USA, together with other industrialized economies, eventually went into recession in the second half of 2001, this difference vanished.

Analysis of short-term GDP fluctuations confirms this heterogeneity. The quarterly GDP variations show little correlation across the region as a whole, confirming the results obtained by Cerro and Pineda (2002). An interesting pattern emerges, however, when looking at i) the evolution of the correlation over the 1993-2002 period and ii) the situation within each of the subregions. Not only is the correlation higher when calculated within each subregion, but it also increases over time (table 4).

$\begin{array}{lrcrc}\text { TABLE } 4 & \text { Latin America and the Caribbean: } \\ \text { Quarterly GDP variations, 1993-2002 } \\ \text { (Inter-country correlation coefficients) }\end{array}$

Source: Prepared by the author on the basis of ECLAC data .

${ }^{\mathrm{a}}$ Mexico, Central America and Dominican Republic.

Review of the correlation coefficients obtained for the output gaps (percentage difference between potential and observed GDP) shows that the moderate co-variation of economic activity across the region is nevertheless higher than the coincidence observed in output gaps. This is confirmed by the results of the principal component analysis. As shown in table 5, the first factor has a greater representation power in the case of quarterly variation of total GDP, compared to the output gaps.

These results indicate that although the co-variation of economic activity in the region is still diffuse, it has been increasing over the period studied and in general the Latin American and Caribbean countries have tended to cluster around common subregional patterns. This is quite an interesting feature considering that the correlation of business cycles across countries is an argument in favour of macroeconomic policy coordination and optimum currency areas. ${ }^{11}$ Nevertheless, the weakness of the linkage indicates that the Latin American region is still far from the self-reinforcing situation corresponding to the right part of figure 2 above ( $\mathrm{R}>\mathrm{T}$ ). As a consequence, macroeconomic coordination per se is far from being a sufficient condition for closer integration, and more traditional integration policies have to be maintained and deepened.

\begin{tabular}{|c|c|c|c|c|}
\hline & \multicolumn{4}{|c|}{$\begin{array}{l}\text { Latin America and the Caribbean: Quarterly } \\
\text { GDP variations and output gaps, 1993-2002 } \\
\text { (principal components) }\end{array}$} \\
\hline & Factor1 & Factor 2 & Factor 3 & Factor4 \\
\hline \multicolumn{5}{|c|}{$\begin{array}{l}\text { Quarter to } \\
\text { quarter variation }\end{array}$} \\
\hline Eigenvalue & 4.8 & 2.5 & 1.7 & 1.3 \\
\hline$\%$ variance & 34.2 & 17.9 & 12.5 & 9.1 \\
\hline$\%$ cumulative & 34.2 & 52.2 & 64.6 & 73.8 \\
\hline \multicolumn{5}{|l|}{ Output Gap } \\
\hline Eigenvalue & 3.6 & 2.8 & 2.3 & 1.4 \\
\hline$\%$ variance & 25.5 & 19.7 & 16.5 & 10.0 \\
\hline$\%$ cumulative & 25.5 & 45.2 & 61.7 & 71.7 \\
\hline
\end{tabular}

Source: Prepared by the author.

\footnotetext{
${ }^{11}$ Albeit not a necessary one if one takes into consideration the endogeneity of these OCA criteria, as we already mentioned.
} 


\section{IV}

\section{Institutional criteria for initiating and maintaining coordination}

In the previous sections, we have seen that the Latin American and Caribbean economies show at least some of the necessary conditions for benefiting from macroeconomic cooperation, and that the expected welfare gains are probably a positive function of time. Despite its potential and increasing benefits, however, initiating a programme of policy coordination is only part of the story, as many other challenges remain.

As analysed by Kronberger (2002), even in the case of the endogeneity of the OCA criteria, there are important difficulties to face, especially in the case of emerging economies. In particular, for the endogenous process to initiate, there is a need for a strong political will and a firm political consensus. The following section identifies and briefly comments on some of these issues.

\section{Uncertainty and the size of the "union"}

Defining a common strategy for macroeconomic cooperation between sovereign States faces several obstacles in a real life situation. The first of them, obviously, is the uncertainty about the net outcome of cooperation (balance of costs and benefits of cooperation). As we saw, both traditional and endogenous OCA criteria provide a guide to this aspect, and the prospects for Latin America and the Caribbean are positive, at least at the sub-regional level.

Probably the second most important obstacle is the uncertainty concerning the behaviour of other players: an aspect that can be analyzed from the institutional perspective. As we mentioned earlier, this uncertainty, which is prejudicial to a cooperative outcome in a finite game, can be controlled and reduced by the possibility of committing players, through an enforceable agreement, to adopt a cooperative strategy. In our present case, this would be achieved through treaties regulating international relations between countries, but the difficulty of enforcing contracts (i.e., devising penalties) among sovereign States should not be underestimated.
Demopoulos and Yannacopoulos (2001) incorporate this practical aspect by analyzing the costs and benefits of macroeconomic coordination in the context of a currency area, as a function of its size. As a currency area expands, the benefits from adopting a single currency increase, but not as fast as the difficulties of agreeing on a common set of policies and enforcing them as new countries, with macroeconomic problems of their own, join the area. Because transaction costs are assumed to increase faster than benefits, there is an optimum threshold in terms of the number of participating countries.

From this brief summary it may be deduced that, in the presence of the Prisoner's Dilemma, several key points have to be clarified in order to advance the case for regional cooperation on macroeconomic policy.

The first set of critical factors relates to the nature of costs and benefits. Cooperation should not only be beneficial for all participants, but those benefits must also be sufficiently larger than in the case of an alternative, non-cooperative approach. At the same time, they must be easily identifiable and not too uncertain, in order to define a clear incentive to cooperate.

Second, it must be ensured that there are not too many players, and that they can be induced to accept reasonably binding commitments to cooperate. Building an appropriate institutional framework to provide for suitable commitment technology is a key element in this respect.

These two argument, applied to the Latin American and Caribbean context, point in the direction of a form of cooperation limited -at least initially - to sub-regional partners, and based on a strong regional institutions.

\section{Credibility of national and regional macro-policies}

This institutional commitment technology needed to increase the credibility of the decision agreed upon is key to understanding the importance of a proper 
institutional setting in the design of a sub-regional coordination mechanism. This arrangement, as argued in Escaith, Ghymers and Studart (2002), should include the appropriate monitoring and endorsement/disqualification capacities, and calls for the existence of a formal institutional arrangement at the supra-national level. Such a mechanism must offer national governments a set of positive and negative incentives to cooperate in the coordination of macroeconomic policies, as well as a well-designed negotiation, monitoring and reporting system that creates an effective system of checks and balances.

Also, this institutional commitment must be workable and credible, which means that the conditions and criteria stated earlier regarding the optimal size of an OCA apply also to these aspects. Because the initial benefits Rt may be low and uncertain as long as $\mathrm{t}<\mathrm{t}^{*}$, a strategy of defection of one of the players due to the Prisoner's Dilemma situation is a real possibility. Therefore, a proper formal institutional arrangement will be vital in order for a cooperative game to be sustained. Ideally, the institutional setting must incorporate penalties for non-cooperative behaviour, in order to lower $\mathrm{T}$ and the temptation to defect, as in the European case.

Once the game has been repeated a sufficient number of times, so that credibility has been established and welfare gains have become clear to all players, they will have an incentive to continue, even when transitory conditions provide an incentive to defect. ${ }^{12}$ In addition to the arguments of the endogenous gains from cooperation, one could add that with the passing of time and the building-up of regional institutions, regional integration and policy coordination gain credibility with national and international agents: a key factor in the sustainability of national macroeconomic.

As noted earlier, political economy considerations are taking on an increasing role in the analysis of macroeconomic policymaking. The same trend can be observed in applied development economics, where research brings together the work of economists and political scientists to focus on governance and on the interaction of economic and political factors in the

\footnotetext{
12 As recently exemplified by the European case, regional commitments to reduce the fiscal deficit may be counterbalanced by shortterm national considerations. Nevertheless, member countries, even the largest ones as in the cases of France and Germany, take the political consequences of a regional sanction very seriously and the prospect, and hence the consequences, of a breach of the regional rules have fuelled a strong debate in Europe.
}

making and working of actual policy. As often occurs in developing countries, when competing objectives cannot be reached simultaneously with the current set of policy instruments, policymakers are constrained to second-best solutions. In such a situation, competing objectives must be reached sequentially, and shortterm deviation from pre-announced policies should not be mistaken for an abandonment of initial goals.

This means that the long-term commitments announced by the policymakers must be credible. When the national situation is less than favourable in that respect, policy-takers may be tempted to interpret short-term deviations from pre-announced targets by policymakers as discretional shifts in policy, and hedge against this risk (for example by reducing their demand for national currency). Bringing in the supranational dimension can help to avoid this outcome. Persson and Tabellini (1990) state that the decision to join a supra-national arrangement provides a regional "commitment technology" that gives more credibility to policymakers.

By providing external auditing of the macroeconomic situation, regional monitoring and analysis will help to discriminate between exogenous and endogenous policy shocks when actual inflation deviates from the pre-established target. Provided that regional institutions are sufficiently isolated from national pressures, they would also be instrumental in consolidating the credibility of the national institutions when deviations between ex ante objectives and ex post achievements are unintended and due to external factors. Being regionally negotiated and self-imposed, the ownership factor should help in facilitating the definition of a consensus between policymakers and civil society on the need to respect national commitments, unlike other international monitoring arrangements (e.g., by the International Monetary Fund).

\section{The uncertainty of the model}

Because the application of economic theory to real-life situations is not always unambiguous, there is always a probability of error when adopting a particular model. Uncertainty about parameters and disagreement among coalition partners about the right economic model to follow pose a real challenge to a cooperative economic policy. Policymakers may have different beliefs about how an economy actually works. Disagreement is obviously not an obstacle to cooperation, but because 
of the uncertainty about the "true model", negotiations may lead to the adoption of a wrong model and result in less welfare than non-cooperation.

Uncertainty may reduce the present value of the expected welfare benefits. Translated into the Prisoner's Dilemma perspective, a simple tit for tat strategy to achieve cooperation is collectively stable if, and only if, the weight of the future outcome $w$ in today's decisions is large enough.

On the other hand, -as occurs with the gradual welfare gains from OCAs- part of this uncertainty is endogenously determined and changes with the number of times the "coordination game" is played. In this case, as we shall see, uncertainty is reduced through cooperation (while the expected welfare gains from OCAs are increased). When both policies and models are subject to choice, policymakers have four options: i) they may make no attempt to agree on the appropriate model or to coordinate their policies; ii) they may exchange information or bargain over the model, but make no attempt to choose their policies jointly; iii) they may not discuss which model should be used, but may coordinate their policy choices explicitly (they do not discuss the justification for their policies); and lastly, iv) they may agree both on the choice of the model and on coordination of their policies. Hughes Hallet (1995) shows that disagreement over the model, in a situation of uncertainty, can still be beneficial for policymakers if it leads to an exchange of information, thus reducing with the passing of time the risk of serious losses.

In practice, countries that enter into an active process of macroeconomic coordination do so after an extensive period of dialogue, exchange of information, mutual monitoring and convergence. The European Union is perhaps the best example of this process of reduction of uncertainty through the sharing of information and mutual monitoring. In the Latin American region, there are several examples of similar processes, and in all subregional integration groups, national decision-makers are actively engaged in a dialogue to reduce uncertainty concerning the key parameters of their respective economies.

Usually, the first step is to establish convergence criteria for key indicators (as in the Macroeconomic Monitoring Group (GMM) in Mercosur, or as these indicators were set in the Andean region, the Caribbean or the Central American Common Market). ${ }^{13}$ This process of defining common concept for the monitoring of the respective economies from a regional perspective is an important step in promoting a regional dialogue on key variables, defining transparent criteria and building mutual trust among regional partners: all aspects whose importance cannot be underestimated.

These processes are still at an initial stage, and more efforts should be made to define more precisely the models underlying the national economies and their interactions. This implies specifying the key parameters of each national economy forming part of the subregional group and modelling the interdependence between them. In addition, unlike the countries of the European Union, those constituting the Latin American and Caribbean region are developing economies, i.e., economies where the key parameters and the systemic response to impulses are prone to rapid and substantial change. Thus, it is even more important in the Latin American context than in the European Union to maintain close monitoring of the key indicators and foster a common programme of analysis of the reaction functions to external and policy impulses.

${ }^{13}$ See ECLAC (2002a), Chapter V. 


\section{$\mathrm{V}$ \\ Conclusions}

This article has shown that, despite favourable indications, there is still a large gap between the actual dynamic of shock transmission in the region and the demanding conditions sets by pure OCA criteria, even when considering only the subregional dimension. The recent developments in the positive theory of endogenous OCAs, however, indicate that full observance of the OCA concept is not a necessity for the initiation of mutually beneficial coordination. If the dynamic of the cooperative game works well, then the iteration of the cooperative game should naturally guide the countries out of the Prisoner's Dilemma. In the absence of a leader country, cooperation must begin with a (minimum) consensus of the participating countries: a process that calls for a preliminary phase of confidence-building based on dialogue and exchange of information and culminates in a regional agreement. That agreement should include the necessary commitment technology to initiate and maintain the cooperative game at least in the first phase of implementation, when benefits are still diffuse and temptation to defect is strong. This commitment technology should therefore include features that increase both the immediate benefits of cooperation (such as the Structural Funds in the European Union) and the cost of defection (peer pressure from within the region and loss of reputation on international markets).

In this particular framework, the probability of cooperation is enhanced when there are fewer players, when each player's discounting of the future benefits is sufficiently low (i.e., if players are farsighted), when they are interacting frequently, and when the benefits and costs associated with each strategy are well known. Through dialogue and cooperation, systemic uncertainty will be reduced and welfare gains will increase. In this case, the outcome of the iterated Prisoner's Dilemma game will result in the repeated selection of a cooperative strategy in every repetition of the game. In contrast, cooperation breaks down or never even begins when there are too many parties, when players are short-sighted, or when benefit conditions and key parameters are rapidly changing.

From the technical standpoint, regional cooperation is the most appropriate forum when the regional partners' economic policies are themselves the source of externalities, as is the case when instability and lack of credibility in one country cause contagion of neighbouring economies. Thus, providing the regional institutional arrangements function well, regional cooperative solutions are at least comparable -if not superiorto individual national solutions on both technical and institutional grounds.

Translating these theoretical conclusions into practical regional economics, this means that countries which have commercial and financial relations, which interact frequently, and which cannot escape from the consequences their decisions have on their partners, have a strong probability of entering into a cooperative dynamic which will be beneficial for all the cooperating participants and will be stable, at least within the original cluster. All these arguments point in the direction of a subregional arrangement, at least in the early phase of policy coordination. From a more political perspective, the commitment-cum-monitoring technology deriving from subregional negotiation among peers is also easier to legitimate than extra-regional supervision. From a broader perspective, regional cooperation in the face of large external financial shocks is also the most appropriate way to face the asymmetries built into the new international financial system, where purely national answers are notably insufficient (Ocampo, 2001). In the present situation, however, the degree of integration is still too weak for macroeconomic coordination to be self-enforcing. Efforts to promote macroeconomic coordination should be complementary to, and not a substitute for, more traditional policies designed to deepen trade relations and strengthen the institutional structure for integration.

(Original: English) 
Bibliography

Axelrod, R. (1984): The Evolution of Cooperation, New York, Basic Books.

Benavente, J.M. (2001): Exportaciones de manufacturas de América Latina: ¿desarme unilateral o integración regional?, "Macroeconomía del desarrollo" series, No. 3, LC/L.1523-P, Santiago, Chile, ECLAC. United Nations publication, Sales No. S.01.II.G.66.

Buti, M. and A. Sapir (eds.) (1998): Economic Policy in EMU: A Study by the European Commission Services, Oxford, Clarendon Press.

CEI (Centro de Economía Internacional) (2003): Cooperación macroeconómica en el Mercosur: un análisis de la interdependencia y una propuesta de cooperación, Estudios del CEI, No. 4, Buenos Aires, April.

ECLAC (Economic Commission for Latin America and the Caribbean) (2000): Economic Survey of Latin America and the Caribbean, 1999-2000, LC/G.2104-P, Santiago, Chile. United Nations publication, Sales No. E.00.II.G.70. (2001): Economic Survey of Latin America and the Caribbean, 2000-2001, LC/G.2139-P, Santiago, Chile. United Nations publication, Sales No. E.01.II.G.2.

(2002a): Latin America and the Caribbean in the World Economy, 2000-2001, LC/G.2149-P, Santiago, Chile. United Nations publication, Sales No. .02.II.G.6.

(2002b): Current Conditions and Outlook 2002. Economic Survey of Latin America and the Caribbean, 2001-2002, LC/G.2184-P, Santiago, Chile, August. United Nations publication, Sales No. E.02.II.G.71.

Cerro, A.M. and J. Pineda (2002): Do common cycles exist in Latin American countries?, Latin American Research Abstracts, No. 17, Dallas, Center for Latin American Economics, Federal Reserve Bank of Dallas.

Demopoulos, G. and N. Yannacopoulos (2001): On the optimality of a currency area of a given size, Journal of Policy Modeling, vol. 23, No. 1, Amsterdam, Elsevier Science, January.

Escaith, H. and I. Paunovic (2003): Regional Integration in Latin America and Dynamic Gains from Macroeconomic Cooperation, "Macroeconomía del desarrollo" series, No. 24, LC/L.1933-P, Santiago, Chile, ECLAC, July. United Nations publication, Sales No. E.03.II.G.92.

Escaith, H., C. Ghymers and R. Studart (2002): Regional Integration and the Issue of Choosing an Appropriate Exchange-Rate Regime in Latin America, "Macro-economía del desarrollo" series, No. 14, LC/L.1732-P, Santiago, Chile, ECLAC, August. United Nations publication, Sales No. E.02.II.G.86.

Frankel, J. and A.K. Rose (1996): The Endogeneity of the Optimum Currency Area Criteria, NBER Working Paper, No. 5700,
Cambridge, Massachusetts, August.

Ghymers, C. (2001): La problemática de la coordinación de políticas económicas, "Macroeconomía del desarrollo" series, No. 10, LC/L.1674-P, Santiago, Chile, ECLAC, December. United Nations publication, Sales No. S.01.II.G.209.

Hardin, G. (1968): The tragedy of the commons, Science, No. 162, New York, American Association for the Advancement of Science.

Hughes Hallet, A.J. (1995): Policy bargains and the problem of model selection, Journal of Economic Dynamics and Control, vol. 19, No. 5-7, Amsterdam, Elsevier Science.

Kenen, P. (1969): Theory of optimum currency areas: an eclectic view, in R.A. Mundell and A.K. Swoboda (eds.), Monetary Problems of the International Economy, Chicago, University of Chicago Press.

Kronberger, R. (2002): Cost-benefit analysis of a monetary union for MERCOSUR, with particular emphasis on the optimum area theory, Integration and Trade, vol. 6, No. 16, Buenos Aires, Institute for Latin American and Caribbean Integration (INTAL), January-June.

McCallum, B. (1999): Theoretical Issues Pertaining to Monetary Unions, NBER Working Paper, No. 7393, Cambridge, Massachusetts, National Bureau of Economic Research, October.

McKinnon, R.I. (1963): Optimum currency areas, American Economic Review, vol. 53, Nashville, Tennessee, American Economic Association, September.

Mundell, R. (1961): The theory of optimum currency areas, American Economic Review, vol. 51, No. 4, Nashville, Tennessee, American Economic Association.

Ocampo, J.A. (2001): International Asymmetries and the Design of the International Financial System, "Temas de coyuntura" series, No. 15, LC/L.1525-P, Santiago, Chile, ECLAC, April. United Nations publication, Sales No. E.01.II.G.70.

Ocampo, J.A. and M.A. Parra (2003): The terms of trade for commodities in the twentieth century, CEPAL Review, No. 79, LC/G.2200-P, Santiago, Chile, April.

Parrado, E. and A. Velasco (2002): Alternative Monetary Rules in the Open Economy: a Welfare-Based Approach, in N. Loayza and R. Soto (eds.), Inflation Targeting: Design, Performance, Challenges, "Central Banking, Analysis and Economic Policies" series, Santiago, Chile, Central Bank of Chile.

Persson, T. and G. Tabellini (1990): Macroeconomic Policy, Credibility and Politics, Switzerland, Harwood Academic Publishers GmbH.

Studart, R. (2002): Financial integration, instability and macroeconomic performance in the 1990s: some possible perverse links, Santiago, Chile, ECLAC (unpublished). 